\title{
The acquisition of Chinese in bilingual and multilingual contexts
}

\section{Virginia Yip}

\author{
Chinese University of Hong Kong, China
}

\section{Stephen Matthews}

\author{
University of Hong Kong, China
}

\section{Introduction}

As the field of bilingual acquisition has made significant advances in recent years, there has been a surge of interest in the acquisition of Chinese languages in bilingual and multilingual contexts. This article serves a dual purpose: (1) to discuss some theoretical and methodological issues in bilingual acquisition with special reference to Chinese languages as target languages in bilingual and multilingual contexts; and (2) to highlight the important contributions made by the five articles in this volume, with some commentary on the issues raised by each study.

The five articles to be discussed present highly original and dynamic research involving the acquisition of a Chinese language in children acquiring two or more languages simultaneously from birth. The children featured in these studies come from three very different speech communities: Hong Kong, Australia and Paraguay. In most cases, either Mandarin or Cantonese (referred to collectively as Chinese here) is paired with English, with one case study also involving Taiwanese and Spanish. The combination of a Chinese language with English or another European language (such as Spanish in the case of Paraguay) being acquired by children in childhood raises new and challenging questions about bilingual development.

The diversity in the backgrounds of the children featured in this volume provides a window into the complexity of language acquisition across different bilingual and multilingual contexts. These studies provide important results that future work on bilingual development of a Chinese language will have to take into consideration. They are also valuable in contributing to the fast growing body of longitudinal corpus-based studies by expanding the empirical base of bilingual acquisition and addressing theoretical issues of interest to the field at large.

\section{Address for correspondence}

Virginia Yip, Childhood Bilingualism Research Centre, Department of Linguistics and Modern Languages, The Chinese University of Hong Kong, Shatin, Hong Kong SAR. [email: vcymatthews@cuhk.edu.hk]

Acknowledgments

We thank Li Wei and Ruying Qi for organizing the colloquium 'The Bilingual and Multilingual First Language Acquisition of Chinese Children (BAMFLA): Theoretical and Methodological Issues' at the Sixth International Symposium on Bilingualism (ISB6) where parts of this article were presented. This research has been fully supported by the Research Grants Council of the Hong Kong Special Administrative Region, China (Project reference nos CUHK4014/02H, and CUHK 4692/05H, CUHK453808), CUHK direct grant 06/07 and a grant from the Department of Linguistics and Modern Languages at CUHK. 


\section{Significance of the acquisition of Chinese in bilingual and multilingual contexts}

The study of how children acquire two or more languages is of both theoretical and practical significance. We shall discuss the theoretical significance of the acquisition of Chinese in bilingual and multilingual contexts from a typological perspective followed by its practical significance in informing parents and educators of how to nurture bilingualism, especially in immigrant and adopted children.

A major variable in bilingual development involves the pairing of target languages. Among the many possible permutations, some language pairs are typologically and/or genetically distant, while others are closer. By extending the database from pairing English and European languages to typologically unrelated languages with very different structures such as Chinese languages, childhood bilingualism will be better understood. Salient properties of Chinese such as lexical tone, topic prominence, word order, classifiers and null arguments raise new possibilities for interaction between a child's developing linguistic systems. We shall discuss each of these properties in turn. The pairing of a tonal language with a non-tonal one raises new questions such as the interaction between tone and intonation. Case studies of Chinese-English bilingual children may be used to address questions about the development of tone and intonation, such as: Is word stress realized as high tone? And how does sentence intonation affect the realization of tone? In a pioneering study, Light (1977) discussed some striking features of his daughter Claire's 'increasingly Anglicized' Cantonese that were argued to reflect the influence of English in her new linguistic environment upon her arrival in the USA at 16 months. The shift from Cantonese dominance to English dominance in Claire produced anomalies such as 'disintegration' of the Cantonese tonal system with Cantonese sentences taking on an English intonation pattern.

Chinese languages as target languages are of ever increasing interest to language acquisition researchers, and not simply because they are spoken by more than a quarter of the world's population. They are also intrinsically of great linguistic interest because of their genetic and typological distance from Indo-European languages. A well-known typological characteristic of Chinese is topic-prominence, which contrasts with subject-prominence in languages such as English (Li \& Thompson, 1976; Shi, 2000). The acquisition of topic prominence and related structures in Chinese has been investigated in adult second language acquisition (SLA: see Jin, 1994; Yip, 1995; Yuan, 1995) but awaits investigation in bilingual acquisition. Chinese languages also exhibit a unique combination of word orders (Dryer, 2003). For example, only Chinese languages combine SVO word order with relative clauses preceding the noun; when this property is transferred to English in bilingual acquisition, it results in prenominal relatives as in example (1) from Yip and Matthews (2007b): ${ }^{1}$

(1) You buy that tape is English?

(Timmy 2;10;22)

[i.e. 'Is the video tape that you bought in English?']

Cantonese examples are given in the Jyut6Ping 3 romanization system, developed by the Linguistic Society of Hong Kong (Tang et al., 2002) to meet both linguistic criteria and the constraints imposed by computer applications. The IPA and Yale correspondences are given in Matthews and Yip (1994: 400). The numbers at the end of each syllable represent the tone, from 1 (high level) to 6 (low level). 
The example in (1) where the relative clause [you buy] precedes the head noun [that tape] illustrates a striking non-target structure that is not found in monolingual children acquiring English but regularly produced by the Cantonese-English bilingual children. Because of the unique combination of word orders involved, it is found that object relatives are acquired earlier than subject relatives in these children (Yip \& Matthews, 2007a).

Another typological property of Chinese languages is that they are classifier languages. When paired with a non-classifier language such as English, there is evidence that the classifier system may pose problems: in their studies of Cantonese-English bilingual children, Light (1977) and Li and Lee (2002) reported reduction and overgeneralization in the Cantonese classifier system: the children show overuse of the general classifier go3 and incomplete acquisition of the full repertoire of classifiers. How this phenomenon may be related to shift of language dominance is a research question that awaits investigation, since both studies involve increasingly English-dominant children. It will be fruitful for future studies to investigate the difficulties posed by the syntactic and semantic complexity of the classifier system (Matthews \& Pacioni, 1998; Xu, 1998) across different acquisition contexts.

Chinese is a pro-drop language that allows null subjects and objects in a sentence while English is a non-pro-drop language. Null objects in Cantonese turn out to be an important typological property in accounting for the difficulty in acquiring the word order in double object constructions in Cantonese (Chan, this volume). How null arguments develop in bilingual children's Chinese has yet to be investigated, while their development in English due to influence from Chinese is discussed in Yip and Matthews (2007b).

Given the different parts of the world in which children are acquiring Chinese languages, a word of caution is in order when comparing these children across different speech communities. For example, Taiwan Mandarin differs from Beijing Mandarin in striking ways, from phonology to syntax and the lexicon. The variability in the Mandarin input from different adults in various speech communities cannot be overestimated. An example is the series of affricates /ş, tş, tş̧ $\mathrm{h} /$ in Beijing Mandarin, which are not contrastive in the Mandarin spoken in Taiwan (Yang \& Zhu, this volume). An accurate and detailed description of the target Mandarin properties in terms of the different domains is a prerequisite for investigating the acquisition of Mandarin across acquisition contexts.

From an applied perspective, the number of children acquiring the Chinese-English language pair in early childhood is expected to increase enormously as both languages are of high prestige, with English as an international language and Mandarin, in particular, gaining ground as a lingua franca among Chinese people in China, Hong Kong, Taiwan, Singapore and overseas communities (e.g. in Australia, Canada, the UK and the USA). Chinese is rising in prominence as a widely learned second language in many parts of the world; one sign of this is the rapid spread and growth of Confucius Institutes established to promote Chinese language and culture around the globe.

\section{Immigrant and adopted children}

An emerging bilingual population around the world that deserves much more attention is that of Chinese children who move from Chinese-speaking communities to an English-speaking country. They are typically exposed to a Chinese language in the home and acquire the language of the speech community simultaneously or successively. They form a significant 
emerging group that is faced with the challenging task of preserving Chinese as their heritage language and acquiring English as the mainstream language of the community in which they grow up.

Investigating the development of Cantonese in a group of British-born Chinese-English bilinguals aged 5 to 16 who acquired Cantonese as L1 and English as L2 in the UK, Li and Lee (2002) report delayed and stagnated development of Cantonese in the domain of classifiers and quantifiers due to incomplete learning of their L1 Cantonese and the influence of English, a dominant language in the environment. It is likely that noun classifiers and quantification in Cantonese have not been fully acquired in L1 development as language dominance gradually shifts to English.

Though the focus here is on Chinese languages in bilingual development, equally interesting and important is the development of English in these immigrant settings especially since balanced development is a concern for parents and educators. Jia (2006) discusses the L2 acquisition of English in Chinese children from immigration families in the USA, suggesting that younger learners tended to switch their dominant language from L1 to L2 while leaving certain features of English morphology and syntax unacquired. In particular, such learners often fail to fully acquire morphological features, such as plurals and verb agreement, as well as articles (Jia, 2006: 67). Jia and Aaronson (2003) address the issue of switch of dominant language in younger learners and language maintenance in older learners in a longitudinal study where the age of arrival of Chinese children ranged between 5 and 16 .

The practical importance attached to the study of childhood bilingualism includes informing parents and educators about how to bring up bilingual children successfully. Nurturing bilingual children is going to be high on the agenda of early childhood education in many countries across the world and will continue to draw the attention and support that has been growing over the years. In particular, preserving Chinese as the heritage language of immigrant children while nurturing the language of the speech community has become an urgent priority for many parents and educators. A common outcome is that these children become dominant in the second language while Chinese often undergoes varying degrees of maintenance and attrition. With continued exposure to Chinese in an English-speaking environment, these children will stand a good chance of living their life with two languages even as they grow up as adults. Research on Chinese immigrant and adopted children will yield valuable findings that contribute to the growing literature in childhood bilingualism. Basic findings in the field should in turn be made common knowledge to parents and language professionals who wish to be informed.

Another category of children who are drawing increasing attention from the international academic community is that of adopted children, whose language development before and after adoption has become an intriguing domain of inquiry. Recent years have seen the rising number of international adoptions around the world, with China being the number one source of children adopted into the USA. Many of the adoptees from China into American families leave their homeland in infancy, before age two or three, and have to acquire a 'second first language' (Pollock, Price \& Fulmer, 2003; Roberts et al., 2005). In monolingual Englishspeaking homes, it is likely that these children's first language, Chinese, will gradually be lost while English takes over as their first language (Nicoladis \& Grabois, 2002). For those adopted into homes with Chinese spoken regularly and English in the community, some form of bilingualism is likely to develop, with both Chinese and English acquired together. 


\section{Contributions of this volume}

We aim to highlight the major contributions of each of the articles and comment on some specific issues arising in each case. We shall consider the theoretical and empirical basis for each study, and their contributions to the field of bilingual and multilingual acquisition in general. Our discussion will inevitably leave out many interesting details in each study as we focus on what we consider to be major issues of concern to the field at large.

In conducting research in bilingual and multilingual acquisition, information on the division of input, quantity and quality of input from each language available to the child is crucial: What are the input conditions, and how is the input space divided in each case? Details of each child's input conditions are needed in order to facilitate comparison of different bilingual and multilingual children. Apart from parental report and estimation, how can the amount of input be measured independently? How do we determine the language dominance of a bilingual or multilingual child and capture the degree of balance or imbalance during the course of development in quantitative terms? Since all five articles make use of corpus data, we shall consider some methodological issues involving the collection and use of corpus data in bilingual acquisition research, noting the usefulness and the limitation of corpus data.

A major theoretical issue involves when and where cross-linguistic influence occurs in bilingual development. We will approach this question by adopting the notion of vulnerable domains (cf. Müller, 2003): What specific grammatical domains in the target language are acquired late and/or with difficulty? To what extent are the developmental trajectory and rate in diverse monolingual and bilingual children similar to and different from each other? What factors can account for the similarities and differences?

\section{Chang-Smith: Mandarin nominal expressions in monolingual and bilingual development}

Chang-Smith (this volume) compares the development of a Mandarin-English bilingual child $(1 ; 08-2 ; 03)$ with that of a monolingual Mandarin-speaking child $(1 ; 08-2 ; 02)$ in a study of nominal expressions in Mandarin. Ralph is a bilingual child exposed to Mandarin and English simultaneously from birth in Australia while Bing is a monolingual child exposed primarily to Mandarin in Taiwan. The study is the first systematic study to document the development of a Mandarin-English bilingual child in a one-parent one-language family.

Definite and indefinite nominal expressions show a salient typological contrast between Mandarin and English. Definiteness and indefiniteness in Mandarin are marked by demonstratives, numerals and in particular classifiers, which form a functional category that is absent in English. Apart from the slight lag between Ralph's production of [demonstrative $+y i+$ classifier] structure and the full-fledged [demonstrative $+y i+$ classifier] structure relative to Bing, the developmental pathway is largely similar for the bilingual and monolingual child. The findings are argued to support the Autonomous Development Hypothesis as transfer from English to Mandarin was not observed in the nominal domain.

The theoretical aim of the study is to compare the predictions of the Autonomous Development Hypothesis and Interdependent Development Hypothesis. The predictions of the Autonomous Development Hypothesis are relatively straightforward: the bilingual child's Mandarin should develop like the monolingual child's Mandarin, and this is claimed to be the 
case in the domain of nominal structure. The predictions of the alternative hypothesis are not so clearly spelled out, and would seem to us depend on what kind of constraints are assumed on transfer. In the context of adult Second Language Acquisition, possible views range from full access/full transfer (Schwartz \& Sprouse, 1996) to more constrained views of transfer such as Andersen's 'transfer to somewhere' (1983). In the domain of bilingual development, recent studies have generally assumed some form of structural overlap condition as proposed by Hulk and Müller (2000):

Syntactic cross-linguistic influence occurs only if language A has a syntactic construction which may seem to allow more than one syntactic analysis and, at the same time, language B contains evidence for one of these two analyses. In other words, there has to be a certain overlap of the two systems at the surface level. (Hulk \& Müller, 2000: 228-229)

Whatever one's view of transfer, one needs a testable hypothesis such that transfer might be expected in a given domain, in this case the Mandarin noun phrase: What exactly would we expect to see in the bilingual child's Mandarin if it were influenced by his English? One question of this kind, which is addressed in the study, is whether the child produces nominal expressions consisting of [demonstrative $+\mathrm{N}$ ] such as na che 'that car' or [number $+\mathrm{N}$ ] such as yi che 'one/a car' under the influence of English grammar. However, it is not clear that the overlap condition is met here: although noun phrases of the form [Dem N] such as zhe ren 'this person' exist in formal and written registers of Mandarin, it is doubtful whether children would hear such exemplars. ${ }^{2}$ A related question involves interlingual identification (Yip \& Matthews, 2007b: 39). As Chang-Smith notes, early use of zhege 'this' is not analyzed, whereas in adult usage it can be decomposed into [demonstrative + classifier]. As long as zhege is identified with this, we would expect the child to use zhege ren rather than zhe ren as the equivalent of this person. Any transfer from English would then be positive transfer, indistinguishable from monolingual usage. The findings show that a small number of instances of [Dem N] and [Num N] are recorded in both the bilingual Ralph and the monolingual Bing's production. Qualitative analysis of these crucial instances would be called for in order to determine whether they are similar in kind.

As noted in the study, Ralph appears to be a relatively balanced bilingual, with no obvious dominant language. If this could be demonstrated with a variety of measures, it would help to explain the discrepancy between these findings and those of Yip and Matthews (2007b) where transfer is observed predominantly from Cantonese in children for whom it is the dominant language.

Ralph's data come from an extensive daily record of diary entries from $0 ; 10 ; 16$ to $3 ; 02 ; 07$ while Bing's data come from video recordings over a 4 -month period $(1 ; 08-2 ; 02)$. The enormous quantity of child utterances recorded by the bilingual child's parents is impressive, averaging 68 utterances per day and amounting to some 14,000 during the 33-week period, that is, between the ages 1;08 and 2;03. While the effort to keep 'an almost exhaustive list' of the child's utterances is admirable, contextual information and adult input would need to be

2 Another possibility would be that time expressions without a classifier such as zhe tian 'this day', na nian 'that year' and so on could serve as a basis for overgeneralization of [Dem N], given the superficial overlap with English. 
recorded to complete the picture. It is an advantage that regular video recordings were made to complement the diary records. Child utterances alone without contextual information and adult interaction could potentially raise questions of ambiguity, making interpretation of the data difficult. A great deal of ambiguity can be disambiguated by means of context and adult utterances preceding and following the child utterance. Analysis of referential properties of nominal expressions such as definiteness, indefiniteness, specificity and non-specificity hinges on what the child refers to in the context. It is thus a challenge to determine the formmeaning mapping between a given nominal expression and its referent without the benefit of contextual information.

Another methodological issue has to do with the calculation of Mean Length of Utterance (MLU) on the basis of diary entries. To the extent that diary entries tend to record what is noteworthy rather than the whole of the child's production, it would be problematic to calculate MLU on the basis of this potentially non-representative sample of utterances. Unlike in a transcript with say half an hour of interaction on the basis of which MLU values can be computed with a relatively large sample, diary data pose challenges for systematic calculation of MLU.

The analysis of Ralph's English development is left for future study, which should provide important clues to questions regarding the relationship between language dominance and cross-linguistic influence. If indeed it can be demonstrated with appropriate quantitative measures that Ralph is a balanced bilingual child, this would strengthen the interpretation of the findings with regard to autonomous development and degrees of balance in bilingual development.

\section{Qi: Acquisition of pronouns in a Mandarin-English child}

Qi (this volume) investigates the acquisition of pronouns in a Mandarin-English child whose parents are both native speakers of Mandarin and second-language speakers of English. The child J grew up in Australia where English is the language of the wider community and Mandarin is the home language. Instead of one parent consistently speaking one language as in Chang-Smith's study, the input is conditioned by environment, hence one-environmentone-language. This pattern is typical of immigrant families where both parents are Chinese speakers. The division of input is estimated such that the ratio of Mandarin to English exposure is 3:1 from birth to 2;8, while thereafter the amount of English input increased to almost 1:1 and eventually began to exceed the Mandarin input. By actually estimating the hours of input in each language per day (Qi, this volume, Table 2), this study sets an example that future researchers will do well to follow. As one would expect given these input conditions, the child's Mandarin is his stronger language, as evidenced by MLU (Qi, this volume, Tables 3 \& 4).

This innovative study gives a detailed developmental profile of a bilingual child's pronoun system from $3 ; 0-4 ; 4$, based on a corpus consisting of audio recordings and diary records. The study is based on 1646 child utterances between age 3;0 and 4;0, on average about 20 to 30 minutes of recording, which means altogether around 17 hours of recording. Another 552 utterances are documented in 15 files from 4;0 to 4;4. Given that this is a one-environmentone-language situation, one may wonder how data from each language are elicited. Do the parents switch from one language to the other in the recording session at home, or do they code-mix to varying degrees? To what extent is the bilingual child sensitive to the language context and language choice and does he tend to respond to an English question in Mandarin and a Mandarin question in English? 
The comparison of the pronoun system in Mandarin and English shows that Mandarin pronouns are simpler in formal features, with no gender and animacy distinctions, and no grammatical case with one regular plural morpheme-men.

Another typological feature that sets Mandarin apart from English is null arguments: Mandarin actually prefers null arguments in many places where English requires an overt pronoun. Given any language pair, the child needs to acquire the referential properties of pronouns as well as constraints on the grammaticality of pronouns in different syntactic contexts.

The results show a delay in the emergence of first and second person pronoun reference relative to Mandarin and English monolinguals. English pronouns turned out to pose no major difficulties, while Mandarin pronouns show various non-target usages such as reversal of first and second person forms. The order of emergence for Mandarin pronouns is found to be as follows: third person singular $t a \rightarrow$ first person singular $w o \rightarrow$ second person singular $n i \rightarrow$ first person plural women. This order of emergence contrasts with monolingual studies in which first person wo emerges first. The late emergence of wo3 in J's case appears to be related to the use of his name to refer to himself, thereby avoiding the pronoun, up to about 3;02. These self-referring names co-exist with wo 'I' for an extended period of time, raising some questions: What determines the choice? And why the abrupt change around 3;02?

It is also interesting that J used self-referring names in Mandarin but not in English (Qi, Dibiase \& Campbell, 2006): this could be an effect of input, to the extent that self-referring names are used more extensively in Chinese than English. In Chinese child-directed speech, it is common to refer to oneself using a name and/or a kinship term such as Mama bang ni 'Mommy (I) help you'. This hypothesis could be tested against the adult input in corpus data. A relevant finding reported by Chang-Smith (this volume) is that the bilingual child Ralph she studied preferred proper names over personal pronouns for reference to himself and other people. Pronoun reversal with second person $n i$ 'you' used for the first person wo 'I' was frequently found in his data throughout the study, unlike the monolingual child Bing who made no such reversal errors.

In English, by contrast, J's development follows monolingual norms, with first person pronominal reference followed by second and third person. Qi reports error-free development of the English pronoun system, suggesting that bilingual children's ability to focus on formal aspects of language facilitates the acquisition of certain grammatical properties relative to monolingual children.

In interpreting her findings, Qi suggests that the child follows a trial-and-error and analytic approach to Mandarin - his stronger language, while he takes an error-free route and synthetic approach toward English - his weaker language. We would suggest a possible interpretation of the findings as follows. A subset of children show pronoun reversal in their first language, as J does in his Mandarin. By the time the child is using pronouns productively in the weaker language, J understands the deictic functions of pronouns based on the first or stronger language. The indexical function of pronouns has already been worked out in the stronger/first language, and this knowledge can be transferred to the weaker/second language. To test this view, it would be of interest to investigate whether balanced bilingual children who show pronoun reversal also use the same strategy in the other language.

A final point we would make about this area is that, as Qi notes in her conclusions, pronoun reversal is puzzlingly sporadic. This suggests to us a need for controlled experiments, 
which should provide a clearer picture of the child's knowledge of pronominal reference. By manipulating the complexity of stimuli, an experimental approach would also allow for testing of Qi's hypothesis that pronoun reversal is related to performance demands rather than to linguistic or cognitive immaturity.

The next two articles to be discussed investigate different aspects of the acquisition of dative constructions in Hong Kong bilingual children exposed to Cantonese and English from birth in one-parent one-language families. Four of the children are Cantonese-dominant (Timmy, Sophie, Alicia and Llywelyn) and one English-dominant (Charlotte), and the oldest child Kathryn more or less balanced. The data come from the Hong Kong Bilingual Child Language Corpus (Yip \& Matthews. 2007b), a large-scale multimedia corpus currently containing seven bilingual children's longitudinal data from 1;3 to 4;6.

The question of what can and cannot be learned on the basis of input is taken as central to the study of child language acquisition (Gathercole \& Hoff, 2007). However, this central question has not been widely addressed in the literature on bilingual acquisition. The role of input frequency in language acquisition is a topic that generates controversies depending on one's theoretical persuasion (Yang, 2004; Lieven \& Tomasello, 2008). Under the usagebased approach, token frequency assumes a critical role in facilitating the entrenchment of the target structures. It follows that frequency information on the dual input will give us a more nuanced and precise picture of how the input space is divided in bilingual acquisition (Paradis \& Genesee, 1996).

\section{Chan: The role of input in Cantonese-English bilingual development}

Chan (this volume) examines the properties of input directed to bilingual children in light of the usage-based approach to child language acquisition. This is a timely move, bringing an increasingly influential approach in first language acquisition to bear on the field of bilingual acquisition. Unlike nativist models, the usage-based approach attaches a great deal of significance to the role of input, taking frequency of exposure and consistency of form-meaning seriously. Researchers interested in exploring input properties and form-meaning mapping will find this approach attractive. While the potential contributions of usage-based approaches to bilingual acquisition are largely unexplored given the development of the field thus far, researchers are increasingly aware of the need to delve into both qualitative and quantitative aspects of input in bilingual and multilingual contexts. Applying the usage-based approach to bilingual acquisition studies can open up new vistas when a large corpus with both child utterances and adult input is available for systematic analysis.

The usage-based approach inspires Chan to investigate three aspects of language use in the input: (1) the token frequency of the target double object construction with bei2 'give' in the adult Cantonese input to the bilingual children; (2) the consistency, or lack thereof, in form-meaning mapping between the target word order and the semantics of the transfer event; and (3) the overlap between the [V-R[ecipient]-T[heme]] word order of the English double object construction and non-target [bei2-R-T] order in developmental Cantonese.

The longitudinal corpora used in Chan's pioneering study allow us to address questions related to adult input in a systematic manner. Chan compares the token frequency of the adult Cantonese utterances, utterances with bei2, and the target bei2 double object constructions 
in the two groups of children. She shows that the target full dative constructions (with both objects in situ following the verb 'give') form a minority of the tokens containing bei2 'give' in the input. A major reason for this is a typological property of Chinese discussed earlier: the prevalence of null arguments, so that in a double object construction the theme object is frequently null, as in the adult utterance in example (2):

$\begin{aligned} \text { (2) INV: } & \text { Bei2 ngo5 } \\ & \text { give me } \\ & \text { 'Give (it) to me.' }\end{aligned}$

$\begin{array}{llllll}\text { CHI: } & \text { Bei2 jat1 go3 bei2 ngo5, } & \text { jat1 } & \text { go3 } \\ & \text { give one } \text { CL } & \text { give me } & \text { one } & \text { CL } \\ & \text { 'Give one to me, one ...' }\end{array}$

(Alicia 1;11;05)

The adult sentence fails to show where exactly the theme object belongs: before, or after the recipient? That is, faced with $[\mathrm{V}-\mathrm{R}]$ as in the foregoing example, it is not clear whether the underlying structure would be [V-(T)-R] or [V-R-(T)]. Moreover, such sentences present the recipient immediately following the verb, creating an apparent [V-R] complex. This leaves the surface order [bei2-R] ambiguous with regard to the placement of the theme argument, and the mapping of form to meaning less than consistent. The input is thus not conducive to error-free acquisition, even for monolinguals, who are shown to produce non-target [bei2-R-T] constructions as a developmental stage. For a bilingual child, the proportion of the input (as well as the absolute number of tokens) instantiating the target construction is correspondingly smaller and the problems posed by this domain of grammar are exacerbated. Furthermore, the predominant [bei2-R] configuration in Cantonese overlaps with the consistent [V-R-T] order in English.

\section{Gu: Bidirectional influence in syntax}

In a related study, $\mathrm{Gu}$ (this volume) investigates the acquisition of Cantonese and English dative constructions in the same group of bilingual children, arguing that bi-directional cross-linguistic influence is evidenced in their development. While Chan's study focuses on the children's Cantonese, Gu looks at the order of emergence of dative and related structures in both languages, comparing bilingual children with their monolingual counterparts in terms of the time lag in the emergence of the related structures and the quantitative and qualitative differences between the two groups of children.

As long as the acquisition of both languages is in progress, the possibility for the bilingual child's two simultaneously developing linguistic systems to interact arises. Either language may influence the other as many structures and properties are still to be acquired in each. Gu's findings argue for bidirectional influence in a complex grammatical domain: while English [V-R-T] double object constructions may strengthen and entrench the non-target Cantonese [bei2 'give'-R-T] constructions, Cantonese serial verb constructions of the form [V-bei2-NP-NP] are transferred to English and realized as non-target prepositional datives with the form [V-PP-NP].

A key theoretical issue driving Gu's study involves the derivational relationship between double object datives and other related constructions in each language. A number of theoretical 
analyses have been proposed positing serial verb constructions as the underlying structure of bei2 'give' double object datives in Cantonese, while others argue for different derivational relationships between double object and prepositional datives in English. In Cantonese, the evidence suggests that serial verb constructions serve as the basis for deriving the bei 2 'give' double object construction in monolingual, but not necessarily in bilingual children. In English, double object constructions emerge before prepositional datives in both monolingual and bilingual children, with a much wider time lag in bilinguals. The emergence of prepositional datives in English may be related to when directional to is acquired.

The dative construction with theme preceding recipient [V-T-R] has often been singled out as an 'aberrant' property of Cantonese, topping the list of grammatical points of divergence from Mandarin (e.g. Chao, 1968; Browning, 1974). The term 'Inverted Double Object Construction' for Cantonese (Tang, 1998) reflects the perception that the order [V-R-T], as in English and Mandarin, is normal for dative object constructions, while the order [V-T-R] as in Cantonese is exceptional, hence 'inverted.' Furthermore, bei2 is the only dative verb in Cantonese whose objects appear in the 'inverted' order (Tang, 1998). Other dative predicates, such as gei3 'send' and maai5 'buy', are used in a serial verb construction together with bei2 'give' as the second verb: ${ }^{3}$

\section{(3) Ngo5 gei3 seon3 bei2 keoi5 \\ I mail letter give him \\ 'I send him a letter.'}

Gu suggests that the unique word order seen with bei2 'give' is connected with this serial verb construction. Children typically attempt to use bei2 'give' in the serial verb construction, as in the bilingual child's (4):

(4) Bei2 jat1 go3 bei2 lei5 aa1
give one CL give you SFP

(Sophie 2;11;18)

'(I) give you one.'

While this strategy is not fully grammatical in adult Cantonese (because of the repetition of bei2), it may be a precursor to the target construction. Developmental evidence that the Cantonese [V-T-R] order is based on a serial verb construction, and on [bei2 NP bei2 NP] in particular, comes from production of [bei2-T-bei2-R] as in (4) by both monolingual and bilingual children (Chan, 2003; Gu, 2007). In 7 out of 8 monolingual children, the serial verb construction as in examples (3) and (4) is attested earlier than the double object datives which are hypothesized to be derived from it (Gu, this volume: Table 8). The bilingual children do not show such a consistent pattern: while most of them are found to produce serial verb constructions, these do not consistently precede the double object constructions. Some bilingual children apparently never fully acquire the target [bei2-T-R] double object construction, continuing to use the non-target [bei2-R-T] in accordance with English syntax (Yip \& Matthews, 2007b: 214).

3 The morpheme bei2 in this position can also be analyzed as a preposition, though this does not necessarily affect the argument (Matthews, 2006: 77). 
In English, double object constructions are normally acquired earlier than prepositional dative constructions (Snyder \& Stromswold, 1997; Viau, 2006). Gu shows that the bilingual children also follow this progression. Documenting the time-lag between the age of emergence of double object datives and prepositional datives, she finds a wider temporal gap in bilingual children's English relative to monolingual children. Gu suggests that this delay may be due to the ambiguity of the preposition in different constructions instantiated in the input: directional to is found to occur as a precursor of prepositional dative, emerging after double object but before prepositional dative. ${ }^{4}$ The average temporal gap of over 6.7 months between the emergence of directional to and prepositional datives is much greater than the gap of 0.9 months in monolingual English-speaking children.

Another striking finding is that two bilingual children produced non-target [V-PP-NP] structures (5) in English, alongside a similarly non-target [V-bei2-NP-NP] structure in their Cantonese (6):

(5) I buy $\left[_{\mathrm{pp}}\right.$ for you] $\left[_{\mathrm{NP}}\right.$ the bear] okay?

(Sophie 2;05;30)

(6) Lei5 maai5 [bei2 ngo5] [go3 syut3gou1]

(Sophie 2;08;22)

You buy for me CL ice-cream

'You buy ice cream for me.'

Given the parallel non-target dative constructions in both languages, transfer could in principle be operating in either direction. Yip and Matthews (2007b: 213) suggest that the configuration seen in example (6) is entrenched in the child's Cantonese, and this is transferred to English in $(5){ }^{5}$

Taken together, Gu's findings demonstrate bi-directional influence where the two developing languages interact with each other in the domain of dative constructions. The higher frequency of non-target [bei2-R-T] dative constructions in bilingual relative to monolingual children's Cantonese and the production of Cantonese-based prepositional datives in bilingual children's English which are not found in monolingual children suggest that Cantonese bei2 datives and English prepositional datives are vulnerable domains whose relationship with language dominance has yet to be investigated. Both Chan and $\mathrm{Gu}$ provide qualitative and quantitative analysis of the relevant phenomena, contributing to an emergent literature on vulnerable domains across different acquisition contexts and making highly original proposals that account for why Cantonese bei2 'give' datives and English prepositional datives constitute vulnerable domains in language acquisition.

4 The hypothesis that the acquisition of GO in directional to as a crucial step to progress from double object dative to prepositional dative in bilingual children is motivated by the theory of semantic decomposition whereby prepositional datives can be decomposed into primitives CAUSE and GO, and double object datives into CAUSE and HAVE (Viau, 2006).

5 Another possibility is that the child is influenced by the placement of benefactive PPs in Cantonese:

(i) Ngo5 tung4 lei5 maai5 zek3 hung4zai2

I for you buy CL bear-small

'I buy a bear for you.'

Although the word order is not identical, the child's English utterance could be a compromise between the Cantonese and the English construction with the PP last. 


\section{Yang and Zhu: Early phonological development in a trilingual child}

Yang \& Zhu (this volume) stands out as the sole trilingual case study alongside the bilingual studies already reviewed. This pioneering study of a child's phonological development in Spanish, Mandarin and Taiwanese provides original data in support of transfer between the three languages, while also demonstrating evidence for early language differentiation.

The case study is described as a one-parent-one-language situation within a trilingual family. While this statement may appear paradoxical, it is not unusual in Chinese families for a grandparent to be actively involved in care-giving and to speak a third language natively, thereby contributing to a multilingual context. In Singapore and Hong Kong as well as Taiwan, the third language is commonly a 'dialect' having lower prestige and status, in this case Taiwanese. Yang and Zhu's case study therefore represents a common, even classic acquisition environment in the Chinese context (cf. Gupta, 1994; Yip and Matthews, 2007b: 10). This exposure may result in passive knowledge, as in the case of the Chiu Chow dialect spoken by the grandmother of the siblings investigated in Yip and Matthews (2007b: 64), Chan (this volume) and $\mathrm{Gu}$ (this volume); or it may result in a weaker language, as in the case of Yang and $\mathrm{Zhu}$ (this volume) where Taiwanese input came from family friends as well as the grandmother.

The methodological challenges of investigating trilingual development are formidable, including keeping track of three developing languages, which may be more or less distant genetically and/or typologically, on top of the usual variables such as input conditions and language dominance. In a trilingual environment, distribution and measurement of input become especially crucial (cf. Bosch \& Sebastián-Gallés, 1997; Werker, Weikum \& Yoshida, 2006), and a balanced trilingual will be even rarer than a balanced bilingual. In this study, distribution of input to the child is estimated to be 40 per cent Spanish, 40 per cent Mandarin and 20 per cent Taiwanese. In production, the child's utterances consist of 54 per cent Spanish, 39 per cent Mandarin and 7 per cent Taiwanese. Across the period of study from 15 to 24 months, a total of 184 Spanish words, 163 Mandarin words and 72 Taiwanese words were collected by audio recording. One might wish to know more about how the number of words increases over the course of development from 1;3 to 2;0. Does the child start producing words in all three languages in the same recording at different rates, or is there a longer silent period for the production of Taiwanese? Since the total number of Taiwanese words is less than half of that in Spanish and Mandarin, it raises the issue whether the denominator is large enough in the calculation of percentage of target sounds (see Yang \& Zhu, this volume, section 5.3). As the three quantitative measures of speech accuracy are calculated by dividing the target sound (consonant/vowel/phoneme) by the total number of consonants in each language in the sample, it follows that if both the base number and number of correct target sounds are small, the accuracy could be inflated, thus yielding the surprising result that Taiwanese (the child's weakest language) emerged as the language with the highest speech accuracy (see Per cent Consonant Correct (PCC), Per cent Vowel Correct (PVC) and Per cent Phoneme Correct (PPC) in section 5.3).

Speech accuracy is assessed in terms of vowels, consonants and phonemes correctly produced. It could be that the higher accuracy of Taiwanese sounds is a result of using a small sample size of 72 words (and their consonants/vowels) as denominator, especially if the child tends to produce the highly frequent, least complex sounds of the language.

The lead-lag in emergence of the same or similar sound between the child's languages is both interesting and somewhat unexpected in some cases. For example, /f/ emerges at 
1;6 in Spanish but is not produced in Mandarin before the age of two. What, if anything, is preventing positive transfer from Spanish to Mandarin in this case? The lack of /f/ in the Taiwanese phoneme inventory may be playing a role here.

The pairing of Spanish and Chinese languages allows us to view an innovative pattern of phonological development not previously documented: the replacement of $/ y /$ by $/ \mathrm{i} /$ in Mandarin and deletion of /s/ in word-final position in Spanish. Could this be the effect of Mandarin and Taiwanese 'ganging up' to influence the child's Spanish? The child D was found to use /i/ to replace /y/, an error pattern that seems to be different from either monolingual children or other bilingual children speaking Spanish and other Indo-European languages.

Some phonological processes are found across all three languages, for example, final consonant deletion. In particular the deletion of /s/ in Spanish is singled out as a unique feature in the trilingual child speaking Spanish together with two Chinese languages (Mandarin and Taiwanese). Unlike bilingual children who produced more word-final phonemes (/s/ especially) in the acquisition of Spanish and other Indo-European languages (Garlant, 2001), the trilingual child tends to delete /s/ in the word-final position in Spanish.

Another interesting finding is D's replacement of /1/ with a flap / $/$ in Mandarin and Taiwanese, reflecting the sociophonetic variation between the flap $/ \mathrm{r} /, / \mathrm{I} /$ and the trilled/r/ which are used in free variation among Chinese immigrants in Paraguay. For example, the Mandarin word for mouse /lao şu/is produced as [ $\mathrm{rao} \mathrm{su}$ ] by the child at 1;9 and the Taiwanese word for comb /lua/ is produced as [rua] at 1;10;30. Why did/r/ replace /1/ in Mandarin and Taiwanese? How long does this pattern last and how is it eventually resolved? Does this pattern occur in monolinguals or Mandarin-Taiwanese bilinguals? At the same time, $/ 1 /$ is acquired in Spanish without apparent difficulty, presumably because of the consistent use of the sound in the father's standard Paraguayan Spanish. The trill /r/ in Spanish is replaced with the flap/r/, which is used to replace sounds with shared features across the three languages. Interaction between the three languages can be viewed here as /1/ exists in the three languages but the child's treatment of $/ 1 /$ is different according to language-specific properties: while $/ 1 /$ is in free variation with $/ \mathrm{r} /$ and $/ \mathrm{r} /$ in Mandarin and Taiwanese as evidenced in the idiosyncratic properties of Chinese adult input, /1/ is not interchangeable with other sounds in his Spanish, again in accordance with the properties of the father's input.

The overall results produce some striking findings: although the least amount of input comes from Taiwanese, its sounds are produced with statistically higher accuracy than those of Spanish and Mandarin which are heard more frequently in the overall input. It may come as a surprise that the Taiwanese inventory develops faster than the Mandarin inventory, raising an intriguing issue regarding the advantage of language-specific sounds in phonological acquisition. If amount of input were the sole determinant of rate of acquisition, it would have been a real surprise that Taiwanese sounds are produced earlier and with greater accuracy than Mandarin in spite of the tip in balance of input in favor of Mandarin. The advantage of Taiwanese is accounted for by phonological saliency, defined by Zhu and Dodd (2000) and Zhu (2002) as a syllable-based, language-specific concept. This favors Taiwanese which has 16 consonants, the least number of consonants in comparison with 19 consonants in both Mandarin and Spanish.

Some questions might be raised here about phonological saliency - how is it determined? In terms of a hierarchy/continuum? And how does it interact with other factors such as language dominance and overlap between phonological systems? The consonants successfully acquired 
in Taiwanese are also present in the child's Spanish and/or Mandarin inventory. And what of the missing sounds, yet to be acquired at age two: What is the developmental pathway toward the complete acquisition of the three phonological systems, and what are the mechanisms that enable the child to achieve the feat? As is to be expected in such ground-breaking research, this study raises as many questions as it answers.

\section{General discussion}

Yip (2007) and Yip and Matthews (2007b in preparation) draw attention to issues involving the quantity and quality of input in relation to the bilingual child's ultimate attainment of linguistic knowledge in two respects: (1) How does the division of input reduce the amount and frequency of input in each language relative to monolingual children? (2) What are the ambiguities that may arise in the dual input? How do reduced frequency of input and input ambiguity together shape the developmental pathway and ultimate attainment of bilingual children in achieving a similar state of linguistic knowledge as their monolingual counterparts, while showing delay and lack of convergence with the target grammar in some domains?

Regardless of theoretical frameworks, from nativist to emergentist, the logical problem of language acquisition arises in the context of bilingual acquisition: how the bilingual child bridges the gap between the impoverished input and the complex knowledge of two languages attained. From an emergentist perspective, O'Grady (2005: 184) acknowledges that even in monolingual acquisition, 'The facts are too complex, the input too sparse, mastery too rapid, and errors too infrequent. Induction from experience is not the answer.' Given this characterization of the problem, we contend that in bilingual acquisition the facts are at least twice as complex, and the input twice as sparse. In bilingual acquisition, the rapidity of acquisition and the frequency of errors vary across individuals to a much greater extent than in monolingual children.

The other side of the logical problem involves asking why in certain restricted domains the bilingual child does not converge on the adult grammar: for example, the non-target [bei2-R-T] form described by Chan (this volume) remains entrenched in the bilingual children's Cantonese. The notion of vulnerable domains has been invoked to refer to particular phenomena that are acquired late and often produced in a non-target manner (Müller, 2003). Vulnerable domains are contrasted with invulnerable (or less vulnerable) ones which are acquired early and are relatively free of errors. Which grammatical domains are vulnerable can be identified on the basis of the relevant acquisition data. While the vulnerable domains for each language call for detailed description, the problem of explaining vulnerability remains challenging. Cantonese bei2 datives and English prepositional datives are candidates for vulnerable domains, as argued by Chan and $\mathrm{Gu}$ (both this volume). They pose problems of learnability as many factors conspire against the acquisition of the target structure.

The identification of language-specific vulnerable domains in Chinese languages will no doubt remain a productive topic of research in bilingual acquisition. To achieve a better understanding of the nature of vulnerability of these domains, the inherent grammatical properties vis-à-vis the other language acquired by the bilingual child, their typological differences and universal properties, how cross-linguistic influence interacts with the vulnerability calls for systematic investigation.

With regard to the question of autonomous vs. interdependent development, as it is formulated by Chang-Smith, the findings of the studies reviewed here are mixed. Chang-Smith 
herself sees evidence for autonomous development, with no interaction observed in the domain studied; Qi does observe differences between monolingual and bilingual Mandarin, but these are not attributed to interactive development. Chan identifies cross-linguistic influence in a specific 'vulnerable domain'-the Cantonese bei2 'give' dative construction, where the influence is from English to Cantonese despite the overall dominance of Cantonese over English. She argues that three aspects of the dual language input conspire to make the dative a vulnerable domain. In the same grammatical domain, by scrutinizing the children's English as well as their Cantonese, Gu argues for bidirectional transfer, including cases of transfer from non-target Cantonese to non-target English as in examples (5) and (6). Another domain where overlap between the systems and bidirectional influence is seen in the same children, is that of verb-particle constructions (Yip \& Matthews, 2007b: 216-222; Wong, 2010).

If bidirectional influence can be found in bilingual children, we should expect multidirectional interactions in a trilingual environment: in principle, bidirectional interactions between the three languages permit six distinct directions of influence, not to mention three additional directionalities which might result from two languages 'ganging up' on the third (we suggest a possible case in point later). The six theoretically possible directions in the trilingual situation studied by Yang and Zhu are shown in Figure 1.

\section{Figure 1}

Bidirectional interactions in trilingual acquisition

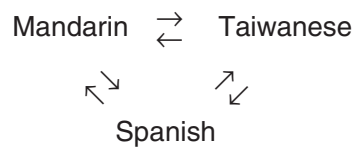

Yang and Zhu find cross-linguistic influence between the child's three developing phonological systems. This is seen in the deletion of /s/ in Spanish, which is singled out as a unique feature in the trilingual child speaking Spanish together with two Chinese languages (Mandarin and Taiwanese). This might be a 'ganging up' effect, as diagrammed in Figure 2.

The possibilities shown in Figures 1 and 2 illustrate how the acquisition of three languages in children is necessarily more complex than that of two languages, and raises new questions.

\section{Figure 2}

A possible 'ganging up' effect in trilingual acquisition

Mandarin $\leftrightarrow \quad$ Taiwanese
$\searrow$ Spanish


Indeed, the conditions on cross-linguistic influence and the directionality of influence are crucial to the emerging field of Third Language Acquisition and Multilingualism (cf. Hoffman, 2001; De Angelis, 2007).

\section{Conclusions and future prospects}

Studying the bilingual acquisition of Chinese and English has helped to address questions such as interactive development, language dominance and mechanisms of transfer. While the current state of the art (as represented by this volume) might seem to suggest that researchers disagree on the issue of autonomous vs. interdependent development, it is increasingly clear that interaction is observed in some children (in at least some domains) and not in others. Much more work is needed in order to understand what underlies these divergences. Possible factors include individual variation, ecological differences in the children's language environment, and methodological differences between studies. Differences in the acquisition environment include:

(a) input patterns: balanced vs. uneven distribution of input; language separation by caregivers vs. language alternation and code-mixing;

(b) family structure: nuclear vs. extended families, single children vs. children with siblings and so forth. Whereas some European studies such as that of De Houwer (1990) take place in a nuclear family, in Chinese speech communities as an extended family remains the norm, with relatives and caregivers other than the parents contributing significantly to the input, as in the study of Yang and Zhu (this volume).

Further questions for future studies include: How do different dominance patterns shape development in different language pairs? What are the effects of factors, such as age of first exposure, imbalance, interruption or temporary deprivation of input? What are the qualitative and quantitative differences between bilingual and monolingual acquisition? How is the simultaneous acquisition of two languages similar to and different from the successive acquisition of two languages in childhood? And to what extent is the difference between the bilingual child's stronger and weaker languages similar to that between a first and second language in childhood second-language acquisition?

With regard to methodology, the five studies reviewed here made use of spontaneous speech data collected by audio and/or video recordings transcribed in corpus format, supplemented in some cases with additional data from parental diary records. While the advent of corpora has made it possible to document aspects of development in detail and quantify them systematically, some caveats need to be kept in mind. Corpora of the kind generally used today at best give only a general, incomplete picture of the complex development of childhood bilingualism. For example, less frequent features and constructions such as relative clauses may not be readily captured using weekly/biweekly recording. Some of these limitations can be overcome by using sufficiently dense corpora (Tomasello \& Stahl, 2004). Increased sampling frequency and duration of recording will produce corpora of higher density that are conducive to refined quantitative analyses and can more readily capture the precise point of emergence and productivity of various grammatical structures. Another solution is to employ experimental paradigms to test children's knowledge of the target constructions in production and comprehension tasks (as suggested for the study of pronominal reference earlier). 
Apart from longitudinal corpus data based on case studies, experimental data are called for to investigate unexplored territory in the areas of language perception, production and comprehension. Studies of language differentiation in phonology, in terms of segmental and suprasegmental features, including tone and prosody, are especially lacking compared to the growing research in the study of development of bilingual lexicon and syntax. The acquisition of tone in bilingual children is one area where studies of Chinese languages can contribute to the overall understanding of bilingual development. For example, Chu (2008) reported interactions between English intonation and Cantonese tone in bilingual children. Another area which awaits investigation in the Chinese context involves code-mixing patterns of bilingual children (Lanza, 2004) and the emergence of structural constraints on code-mixing (Paradis, Nicoladis \& Genesee, 2000).

Finally, the findings reviewed here have mostly been based on children acquiring Cantonese or Mandarin paired with English. Studies investigating childhood bilingualism pairing a Chinese language with a language other than English will be important in extending the empirical database and addressing theoretical issues related to language contact and crosslinguistic interaction. Childhood bilingualism will be better understood when investigated against a rich background of linguistic diversity. Just as bringing a wider range of languages into consideration changes our view of what is possible in human languages, so it promises to change our view of what is possible in bilingual and multilingual development. The bidirectional and multidirectional interactions discussed in this article illustrate a fraction of the possibilities, as it were, the tip of the iceberg.

\section{References}

ANDERSEN, R. (1983). Transfer to somewhere. In Susan Gass and Larry Selinker (Eds.), Language transfer in language learning (pp. 177-221). Rowley, MA: Newbury House.

BOSCH, L., \& SEBASTIÁN-GALLÉS, N. (1997). Infant bilingual language questionnaire. Unpublished instrument, Universitat de Barcelona, Barcelona, Spain.

BROWNING, L. (1974). The Cantonese dialect with special reference to contrasts with Mandarin as an approach to determining dialect relatedness. Unpublished $\mathrm{PhD}$ thesis, Georgetown University.

CHAN, A. W.-S. (2003). The development of bei2 dative constructions in early child Cantonese. Unpublished MPhil thesis, Chinese University of Hong Kong.

CHAO, Y.-R. (1968). A grammar of spoken Chinese. Berkeley: University of California Press.

CHU, C.-K. P. (2008). Tonal development in Cantonese-English bilingual children. Paper presented at the Conference on Bilingual Acquisition in Early Childhood, Chinese University of Hong Kong.

DE ANGELIS, G. (2007). Third or additional language acquisition. Clevedon: Multilingual Matters.

DE HOUWER, A. (1990). The acquisition of two languages from birth: A case study. Cambridge: Cambridge University Press.

DRYER, M. (2003). Word order patterns in Sino-Tibetan. In G. Thurgood and R. LaPolla (Eds.), The Sino-Tibetan languages (pp. 43-55). London: Routledge.

GARLANT, M. (2001). Early phonological patterns of young Spanish-English bilinguals. Unpublished Masters thesis, Arizona State University.

GATHERCOLE, V. C. M., \& HOFF, E. (2007). Input and the acquisition of language: Three questions. The handbook of language development (pp. 107-127). Blackwell Publishers.

GU, C.-J. C. (2007). The acquisition of dative constructions in Cantonese-English bilingual children. Unpublished MPhil Thesis, Chinese University of Hong Kong.

GUPTA, A. F. (1994). The step-tongue: Children's English in Singapore. Clevedon: Multilingual Matters.

HOFFMANN, C. (2001). Towards a description of trilingual competence. International Journal of Bilingualism, 5, 1-17. 
HULK, A., \& MÜLLER, N. (2000). Bilingual first language acquisition at the interface between syntax and pragmatics. Bilingualism: Language and Cognition, 3(3), 227-244.

JIA, G. (2006). Second language acquisition by native Chinese speakers. In P. Li, L. H. Tan, E. Bates, \& O. Tzeng (Eds.), The handbook of East Asian psycholinguistics (pp. 61-69). Cambridge: Cambridge University Press.

JIA, G., \& AARONSON, D. (2003). A longitudinal study of Chinese children and adolescents learning English in the United States. Applied Psycholinguistics, 24(1), 131-161.

JIN, H. G. (1994). Topic-prominence and subject-prominence in L2 acquisition: Evidence of Englishto-Chinese typological transfer. Language Learning, 44(1), 101-122.

LANZA, E. (2004). Language mixing in infant bilingualism: A sociolinguistic perspective. (Extended paperback edition). Oxford: Oxford University Press.

LI, C., \& THOMPSON, S. (1976). Subject and topic: A new typology of language. In C. Li (Ed.), Subject and topic (pp. 457-489). New York: Academic Press.

LI, W., \& LEE, S. (2002). L1 development in an L2 environment: The use of Cantonese classifiers and quantifiers by young British-born Chinese in Tyneside. International Journal of Bilingual Education and Bilingualism, 4(6), 359-382.

LIEVEN, E., \& TOMASELLO, M. (2008). Children's first language acquisition from a usage-based perspective. In P. Robinson and N. Ellis (Eds.), Handbook of cognitive linguistics and second language acquisition (pp. 168-196). Mahwah, NJ: Lawrence Erlbaum Associates.

LIGHT, T. (1977). Clairetalk: A Cantonese-speaking child's confrontation with bilingualism. Journal of Chinese Linguistics, 5(2), 261-275.

MATTHEWS, S. (2006). On serial verbs in Cantonese. In A. Y. Aikhenvald and R. M. W. Dixon (Eds.), Serial verbs: A cross-linguistic typology (pp. 69-87). Oxford: Oxford University Press.

MATTHEWS, S., \& PACIONI, P. (1998). Specificity and genericity in Cantonese and Mandarin. In L. $\mathrm{Xu}$ (Ed.), The referential properties of Chinese noun phrases (pp. 45-59). Paris: École des Hautes Études en Sciences Sociales, Centre de Recherches Linguistiques en Asie Orientale.

MATTHEWS, S., \& YIP, V. (1994). Cantonese: A comprehensive grammar. London: Routledge.

MÜLLER, N. (Ed.), (2003). (In)vulnerable domains in multilingualism. Amsterdam: John Benjamins.

NICOLADIS, E., \& GRABOIS, H. (2002). Learning English and losing Chinese: A case study of a child adopted from China. The International Journal of Bilingualism, 6(4), 441-454.

O'GRADY, W. (2005). Syntactic carpentry: An emergentist approach to syntax. Mahwah, NJ: Lawrence Erlbaum.

PARADIS, J., \& GENESEE, F. (1996). Syntactic acquisition in bilingual children: Autonomous or interdependent? Studies in Second Language Acquisition 18(1), 1-25.

PARADIS, J., NICOLADIS, E., \& GENESEE, F. (2000). Early emergence of structural constraints on code-mixing: Evidence from French-English bilingual children. Bilingualism: Language and Cognition, 3(3), 245-261.

POLLOCK, K., PRICE, J., \& FULMER, K. C. (2003). Speech-language acquisition in children adopted from China: A longitudinal investigation of two children. Journal of Multilingual Communication Disorders, 1(3), 184-193.

QI, R., DIBIASE, B., \& CAMPBELL, S. (2006). The transition from nominal to pronominal person reference in the early language of a Mandarin-English bilingual child. International Journal of Bilingualism, 10(3), 301-329.

ROBERTS, J., POLLOCK, K., KRAKOW, R., PRICE, J., \& WANG, P. (2005). Language development in preschool-age children adopted from China. Journal of Speech, Language and Hearing Research, 48(1), 93-107.

SCHWARTZ, B., \& SPROUSE, R. (1996). L2 cognitive states and the Full Transfer/Full Access hypothesis. Second Language Research, 12(1), 4-72.

SHI, D. (2000). Topic and topic-comment constructions in Mandarin Chinese. Language, 76(2), 383-408.

SNYDER, W., \& STROMSWOLD, K. (1997). The structure and acquisition of English dative constructions. Linguistic Inquiry, 28(2), 281-317. 
TANG, S-W. (1998). On the 'inverted' double object construction. In S. Matthews (Ed.), Studies in Cantonese linguistics (pp. 35-52). Hong Kong: Linguistic Society of Hong Kong.

TANG, S. W., FAN, K., LEE, H-T. T., LUN, C., LUKE, K.-K., \& TUNG, P., (Eds.), (2002). Guide to LSHK Cantonese romanization of Chinese characters (2nd edn). Hong Kong: Linguistic Society of Hong Kong.

TOMASELLO, M., \& STAHL, D. (2004). Sampling children's spontaneous speech: How much is enough? Journal of Child Language, 31(1), 101-121.

VIAU, J. (2006). Give = CAUSE + HAVE/GO: Evidence for early semantic decomposition of dative verbs in English child corpora. In D. Bamman, T. Magnitskaia, \& C. Zaller (Eds.), Proceedings of the 30th Annual Boston University Conference on Language Development (pp. 665-676). Somerville: Cascadilla Press.

WERKER, J., WEIKUM, W., \& YOSHIDA, K. (2006). Bilingual speech processing in infants and adults. In P. McCardle \& E. Hoff (Eds.), Childhood bilingualism: Research on infancy through school age (pp. 1-18). Clevedon: Multilingual Matters.

WONG, H.-Y. H. 2010. The acquisition of verb particle constructions in Cantonese-English bilingual children. Unpublished MPhil Thesis, Chinese University of Hong Kong.

XU, L.-J. (Ed.), (1998). The referential properties of Chinese noun phrases. Paris: École Des Hautes Études en Sciences Sociales, Centre de Recherches Linguistiques en Asie Orientale.

YANG, C. (2004). Universal Grammar, statistics, or both. Trends in Cognitive Sciences, 8(10), 451-456. YIP, V. (1995). Interlanguage and learnability: From Chinese to English. Amsterdam: John Benjamins. YIP, V. (2007). The logical problem of bilingual acquisition. Keynote speech given at the International Symposium on Bilingualism (ISB6) University of Hamburg, Germany.

YIP, V., \& MATTHEWS, S. (2007a). Relative clauses in Cantonese-English bilingual children: Typological challenges and processing motivations. Studies in Second Language Acquisition, 29(2), 277-300.

YIP, V., \& MATTHEWS, S. (2007b). The bilingual child: Early development and language contact. Cambridge: Cambridge University Press.

YIP, V., \& MATTHEWS, S. (in preparation). Bilingual development. Cambridge: Cambridge University Press.

YUAN, B. P. (1995). Acquisition of base-generated topics by English-Speaking learners of Chinese. Language Learning, 45(4), 201-237.

ZHU, H. (2002). Phonological development in specific contexts: Studies of Chinese speaking children. Clevedon: Multilingual Matters.

ZHU, H., \& DODD, B. (2000). The phonological acquisition of Putonghua (Modern Standard Chinese). Journal of Child Language, 27(1), 3-42. 